\title{
The Integrated Pattern Discussion of Leisure Sports Industry and Tourist Industry under the New Normal
}

\author{
Kai Liu \\ Zhuhai College of Jilin University; Zhuhai 519041, China
}

\begin{abstract}
Sports activities have existed in the society for a long time, while leisure sports industry closely related to them has no long history. Nevertheless, the development speed of leisure sports industry has been far exceeded other industries since it appeared. Based on the development characteristics of economic under the new normal, industrial integration must be actively sought for further enhancing the vitality of the development of leisure sports industry. And tourism has a quite strong relevance with it. This paper analyzes the necessity of integration between them from several aspects and probes into the integration pattern of them.
\end{abstract}

Keywords: new normal; leisure sports; tourism; integration.

\section{Introduction}

Industrial integration is a new economic phenomenon, whose appearance is the necessity of the development of the times. The development of economic under the new normal has new characteristics. All industries must readjust the industrial structure and transform the development pattern for ensuring a good and stable development. So industrial integration is an inevitable trend. Leisure sports industry has faced the same problem as well as other industries. Under the current development background of society, people pay more attention to health and increasingly yearn for nature. These middle and high level of demands all depend on the improvement of the residents' living standards. It's an inevitable trend for integration between Leisure sports industry and tourism industry under such specific circumstances. The integration of them can exchange what one has for what one needs for common development.

\section{The Necessity of Industrial Integration Between Leisure Sports and Tourism}

The leisure sports industry has a closely interaction with the tourism industry. Their integration benefits for common prosperity. For both of them are closely related to people's life, most people attach great importance to their health under the social background of increasingly advancements of material life. The leisure sports gradually become an important part of people's life, as well as tourism for its obvious development speed in recent years. Besides, sports and tourism both are corresponding to the middle and high level needs of people, which mean social communication and realization of self value.

\section{1 disadvantages of development of leisure sports industry}

\subsubsection{The long-time shackle of traditional consumption concepts in our country}

Diligence and frugality are insisted by most people in our residents' inherent consumption concepts. It directly causes that the expenditure on spiritual life is much less than that on material life, greatly influencing people's consumption psychology and behavior on leisure sports. What's more, it has become a universal consumption concept in terms of current situation. Therefore, the investment on this area is significantly less than that of other areas.

\subsubsection{Obviously insufficient consumption demand of leisure sports industry}

A large proportion of people influenced by traditional consumption concepts are unwilling to invest excessively on leisure sports, not for available funds being limited. With the continuous growth of our country's economy in recent years, the living life of residents has significantly improved, their disposable income have obviously increased. Even in this economic background, the development of leisure sports industry in our country still comes to a standstill. The primary reason is the bondage of inherent consumption concepts. People are more willing to make a deposit in a bank or invest in real 
estate and other related industries to have appreciations. People always advocate to make both ends meet and moderately consume for being more willing to do relatively conservative things, opposing advanced consumption. These various factors set limits on the development of leisure sports industry.

\subsubsection{Not well-equipped existing facilities of leisure sports}

The existing facilities being not well-equipped hinder the development of leisure sports industry, besides consumption concepts of people. Currently, the leisure sports activities of most people in our country all rely on national sports infrastructure construction, but the related constructions are not perfect. It mainly reflected in the unreasonable allocation of facilities, being mostly in the downtown area while little or no in suburbs. And it is difficult to meet people's diverse demands for leisure sports facilities being relatively single.

\section{2 conditions for integration of leisure sports and tourism}

People start to pursue high-level demands after meeting the necessary living needs, like spiritual needs. So tourism industry has been in a state of good and rapid development in recent years. Leisure sports and tourism have commonness for meeting people's psychological needs. When traveling, people emphasize more on tourism experience, which can be reflected better in sports. Sports activities can provide people with great experience for quite strong participation nature. Besides, Sports activities not only help people to keep fit, but also have entertainment features. The tourism activities and the sports activities coincide naturally in terms of functions, which is the basis of integration of them.

The structure of economic under the new normal will be constantly optimized and upgraded, and the economic driven by elements and investment turns to be driven by innovation. Based on the above, various kinds of industries have been integrated by certain methods to enhance their driving force for development. The integration of tourism industry and sports industry will realize the joint improvement of their self-value, which is the intrinsic motivation of their integration.

\section{3 industrial integration is an inevitable trend}

Industrial integration is an inevitable trend under the development of the times. It can realize complementary advantages and enhance industrial competitiveness through integration. In terms of current situation, the living standards of urban and rural residents in our country have been greatly improved. The leisure sports industry has been demanded to innovate the development modes, actively seek for integration among industries, and develop in innovation while keep innovate in the development, for being imperative to stimulate vitality of leisure sports industry. Tourism industry equally plays a role in the middle and high level demands of people as leisure sports industry, but its development strength is far greater than the leisure sports one. So the investigation of their integration pattern under the new normal economic benefits for a good development for leisure sports industry.

\section{The Content Integration Of Leisure Sports Industry And Tourism Industry}

\section{1 resources integration}

The concept of sports resources have broad sense and narrow sense. The narrow one mainly refers to the related sports facilities, field, equipment and funds. Tourism resources have two main parts which are the natural landscape and the cultural landscape. Sports entertainment belongs to the cultural landscape of tourism resources. The intersection of their both concepts provides necessary conditions with their integration. Many sports activities which can be as tourism resources can be redeveloped. Sports activities with strong ornamental value such as archery, wrestling and horse racing can attract plenty of tourists. So it can be combined with tourism industry, like setting up a fixed location, to make tourists experience themselves with related sports projects while enjoying themselves. It can greatly stimulate their interests on leisure sports activities in this process, and then improve people's demands of leisure sports industry to enhance its pace of development.

\section{2 products integration}

Products integration includes the two following aspects. One is to make leisure sports products settled in the tourist spots. There are similar products on the current market, but what's more important 
is how to make integration better for these products and the tourist spot to attract the tourists. This kind of integration requires to make a concrete analysis of concrete conditions. If there is a locally wide prairie, the related products of horse racing can be brought to the tourist spots. The other is to transform related leisure sports projects into tourist spots. For example, Inner Mongolia Nadam Assembly is a very good tourism resource. The projects of wrestling, horse racing and archery among it surely attract plenty of tourists. Similarly, the sports tourism area can be developed such as leisure sports theme park. It's also a product of their integration.

\section{3 market integration}

The leisure sports industry develops rapidly, but it has low degree of market acceptance. Currently, only a few people have an investment desire in this area, most people depend on the existing public leisure sports facilities of our country. Instead, the tourism industry has been booming. The leading role of market should be made full use in resources allocation in the process of integration. The market integration of leisure sports industry and tourism industry must fully consider their respective brand effect, integrating the related projects of leisure sports industry into tourism industry and transforming them to tourism projects that tourists can experience and enjoy. What's more, marketing innovation is also a key point to promote their market integration. All in all, integrating the two industries by market operation can effectively improve the market competitiveness.

\section{Analysis of Industrial Integration Mode of Leisure Sports and Tourism}

Industrial integration has three ways, which are penetration integration, extended integration, recombination integration.

\section{1 penetration integration among industries}

Penetration integration among industries refers to blend both industries with particular ways and means, such as the development of sports theme park and sports theme block, achieving the interaction with each other and complementary advantages and mutual prosperity. The penetration integration of leisure sports industry and tourism industry can make both gain a good development. Considering the tourism factors into sports can enhance the degree of recognition of people and then psychologically change people's ignorance of leisure sports activities. Leisure and entertainment longed by people in leisure sports and tourism is the basis of their integration.

\section{2 extended integration among industries}

There are some deficiencies in the development of leisure sports industry. Currently, realizing the extension of industry chain is an inevitable trend. Leisure sports industry and tourism industry can make up well for the deficiencies of their own development. The traditional development mode is quite single, and leisure sports industry cannot meet people's diverse demands as a single industry seeking its own development. So leisure sports industry should extend its industry chain and be integrated with tourism industry rather than develop as a single industry. For example, for being lots of traditional sports in our traditional festival, they can be the connecting points to tourism industry. The traditional festival can be as tourists attractions to attract tourists to participate in the related activities, and develop the sports festival tourism industry based on it. Extending the two main industries, like seeking the connecting points to integrate for development, can greatly promote them both develop.

\section{3 internal recombination integration among industries}

Internal recombination integration among industries demands close connections among the integrated industries. There exists this kind of relationship between leisure sports industry and tourism industry, mainly reflecting in that people choosing leisure sports and tourism are both for enjoyment. It illustrates that the two industries are interlinked in the recipients' psychological needs. Meanwhile, sports tourism resource is a kind of tourism resource. It's a relationship of industry and sub industry for them actually. To achieve a steady development of leisure sports industry under the new normal, it's necessary to actively innovate its development mode, seek for industrial integration, achieve the recombination of industry chain and expand market share by internal recombination integration among industries. 


\section{Conclusion}

The economic development strategy of our country under the new normal mainly encourages people to consume to make the development of market economy more dynamic and achieve a sustainable operation of national economy. The development of leisure sports industry should keep pace with the times, actively innovating the development mode and improving their market competitiveness under the development strategy of expanding consumption. In the current development of society, we know that industrial integration is an inevitable trend, and the problems lie in integrating with whom and how to integrate. The consumer groups faced by leisure sports industry and tourism industry have commons in consumption purpose, and both of them can have complementary advantages in the aspects of resources and market. Therefore, their integration can expand industry chain. And with the development of related industries such as leisure sports theme block, it can effectively attract tourists, gain higher degree of recognition of market as well as enhance their market competitiveness. The economic development under the new normal has new characteristics. It's necessary to adapt the transformation of economic mode for striving for better development. In that way, it can effectively enhance the competitiveness and gain a steady development in the market.

\section{References}

[1]. Bao Mingxiao, Zhao Chenglei. The current situation, trend and countermeasure of the development of sports tourism in our country [J]. Sports Scientific Research, 2011, 32(6):4-9.

[2]. Kang Baoling. The interactive research of tourism and sports under the background of industrial integration [J]. Tourism Forum, 2011,3(6):45-48.

[3]. Xing Zhongyou. The research of the development of sports tourism industry in the perspective of industrial integration [J]. Journal of Shan dong Institute of Sports, 2010,26(6):1.

[4]. Lu Changbao, Yu Hairan. The long-term mechanism of abutment of sports industry and tourism industry [J]. Sport Science, 2011,31(9):27-33.

[5]. Chen Baozhu. The research of development and countermeasure of sports and tourism in our country [J]. Journal of Beijing Sport University, 2007,30(1):30-32.

[6]. Wang Jianming. The great potential of integration of sports and tourism [N]. Journal of Chinese Tourism, 2011-12-26. 